\title{
Common fixed points of mappings satisfying implicit contractive conditions
}

\author{
Vasile Berinde ${ }^{*}$ and Francesca Vetro
}

* Correspondence: vberinde@ubm ro

Department of Mathematics and Computer Science, Faculty of Sciences, North University of Baia Mare, 430122 Baia Mare, Romania

\section{Abstract}

In this article we obtain, in the setting of metric spaces or ordered metric spaces, coincidence point, and common fixed point theorems for self-mappings in a general class of contractions defined by an implicit relation. Our results unify, extend, generalize many related common fixed point theorems from the literature. Mathematics Subject Classification (2000): 47H10, 54H25.

Keywords: implicit relation, contraction, coincidence point, fixed point, common fixed point

\section{Introduction and preliminaries}

It is well known that the contraction mapping principle, formulated and proved in the Ph.D. dissertation of Banach in 1920, which was published in 1922 [1], is one of the most important theorems in classical functional analysis. The study of fixed and common fixed points of mappings satisfying a certain metrical contractive condition attracted many researchers, see for example $[2,3]$ and for existence results for fixed points of contractive non-self-mappings, see [4-6]. Among these (common) fixed point theorems, only a few give a constructive method for finding the fixed points or the common fixed points of the mappings involved. Berinde in [7-15] obtained (common) fixed point theorems, which were called constructive (common) fixed point theorems, see [12]. These results have been obtained by considering self-mappings that satisfy an explicit contractive-type condition. On the other hand, several classical fixed point theorems and common fixed point theorems have been recently unified by considering general contractive conditions expressed by an implicit relation, see Popa $[16,17]$ and Ali and Imdad [18]. Following Popa's approach, many results on fixed point, common fixed point and coincidence point has been obtained, in various ambient spaces, see [16-25] and references therein.

In [21], Berinde obtained some constructive fixed point theorems for almost contractions satisfying an implicit relation. These results unify, extend, generalize related results (see [2,3,7-16,21,25-38]).

In this article we obtain, in the setting of metric spaces or ordered metric spaces, coincidence point, and common fixed point results for self-mappings in a general class of contractions defined by an implicit relation. Our results unify, extend, generalize many of related common fixed point theorems from literature.

(C) 2012 Berinde; licensee Springer. This is an Open Access article distributed under the terms of the Creative Commons Attribution License (http://creativecommons.org/licenses/by/2.0), which permits unrestricted use, distribution, and reproduction in any medium, provided the original work is properly cited. 
Let $X$ be a non-empty set and $f, T: X \rightarrow X$. A point $x \in X$ is called a coincidence point of $f$ and $T$ if $T x=f x$. The mappings $f$ and $T$ are said to be weakly compatible if they commute at their coincidence point (i.e., $T f x=f T x$ whenever $T x=f x$ ). Suppose $T X \subset f X$. For every $x_{0} \in X$ we consider the sequence $\left\{x_{n}\right\} \subset X$ defined by $f x_{n}=T x_{n-1}$ for all $n \in \mathbb{N}$, we say that $\left\{T x_{n}\right\}$ is a $T-f$-sequence with initial point $x_{0}$.

Let $X$ be a non-empty set. If $(X, d)$ is a metric space and $(X, \preccurlyeq)$ is partially ordered, then $(X, d, \preccurlyeq)$ is called an ordered metric space. Then, $x, y \in X$ are called comparable if $x \leqslant y$ or $y \leqslant x$ holds. Let $f, T: X \rightarrow X$ be two mappings, $T$ is said to be $f$-nondecreasing if $f x \preccurlyeq f y$ implies $T x \leqslant T y$ for all $x, y \in X$. If $f$ is the identity mapping on $X$, then $T$ is non-decreasing.

Throughout this article the letters $\mathbb{R}_{+}$and $\mathbb{N}$ will denote the set of all non-negative real numbers and the set of all positive integer numbers.

\section{Fixed point theorems for mappings satisfying an implicit relation}

A simple and natural way to unify and prove in a simple manner several metrical fixed point theorems is to consider an implicit contraction type condition instead of the usual explicit contractive conditions. Popa $[16,17]$ initiated this direction of research which produced so far a consistent literature (that cannot be completely cited here) on fixed point, common fixed point, and coincidence point theorems, for both singlevalued and multi-valued mappings, in various ambient spaces; see the recent nice paper [21] of Berinde, for a partial list of references.

In [21], Berinde considered the family $\mathcal{F}$ of all continuous real functions $F: \mathbb{R}_{+}^{6} \rightarrow \mathbb{R}_{+}$and the following conditions:

$\left(\mathrm{F}_{1 a}\right) F$ is non-increasing in the fifth variable and $F(u, v, v, u, u+v, 0) \leq 0$ for $u, v \geq 0$ implies that there exists $h \in[0,1)$ such that $u \leq h v$;

$\left(\mathrm{F}_{1 b}\right) F$ is non-increasing in the fourth variable and $F(u, v, 0, u+v, u, v) \leq 0$ for $u$, $v \geq 0$ implies that there exists $h \in[0,1)$ such that $u \leq h v$;

$\left(\mathrm{F}_{1 c}\right) F$ is non-increasing in the third variable and $F(u, v, u+v, 0, v, u) \leq 0$ for $u, v \geq 0$ implies that there exists $h \in[0,1)$ such that $u \leq h v$;

$\left(\mathrm{F}_{2}\right) F(u, u, 0,0, u, u)>0$, for all $u>0$.

He gave many examples of functions corresponding to well-known fixed point theorems and satisfying most of the conditions $\left(F_{1 a}\right)-\left(F_{2}\right)$ above, see Examples 1-11 of [21].

Example 1. The following functions $F \in \mathcal{F}$ satisfy properties $F_{2}$ and $F_{1 a}-F_{1 c}$ (see Examples 1-6, 9, and 11 of [21]).

(i) $F\left(t_{1}, t_{2}, t_{3}, t_{4}, t_{5}, t_{6}\right)=t_{1}-a t_{2}$, where $a \in[0,1)$;

(ii) $F\left(t_{1}, t_{2}, t_{3}, t_{4}, t_{5}, t_{6}\right)=t_{1}-b\left(t_{3}+t_{4}\right)$, where $b \in[0,1 / 2)$;

(iii) $F\left(t_{1}, t_{2}, t_{3}, t_{4}, t_{5}, t_{6}\right)=t_{1}-c\left(t_{5}+t_{6}\right)$, where $c \in[0,1 / 2)$;

(iv) $F\left(t_{1}, t_{2}, t_{3}, t_{4}, t_{5}, t_{6}\right)=t_{1}-a \max \left\{t_{2}, \frac{t_{3}+t_{4}}{2}, \frac{t_{5}+t_{6}}{2}\right\}$, where $a \in[0,1)$;

(v) $F\left(t_{1}, t_{2}, t_{3}, t_{4}, t_{5}, t_{6}\right)=t_{1}-a t_{2}-b\left(t_{3}+t_{4}\right)-c\left(t_{5}+t_{6}\right)$, where $a, b, c \in[0,1)$ and $a+2 b+2 c<1$

(vi) $F\left(t_{1}, t_{2}, t_{3}, t_{4}, t_{5}, t_{6}\right)=t_{1}-a \max \left\{t_{2}, \frac{t_{3}+t_{4}}{2}, t_{5}, t_{6}\right\}$, where $a \in[0,1)$;

(vii) $F\left(t_{1}, t_{2}, t_{3}, t_{4}, t_{5}, t_{6}\right)=t_{1}-a t_{2}-L \min \left\{t_{3}, t_{4}, t_{5}, t_{6}\right\}$, where $a \in[0,1)$;

(viii) $\quad F\left(t_{1}, t_{2}, t_{3}, t_{4}, t_{5}, t_{6}\right)=t_{1}-a \max \left\{t_{2}, t_{3}, t_{4}, \frac{t_{5}+t_{6}}{2}\right\}-L \min \left\{t_{3}, t_{4}, t_{5}, t_{6}\right\}$, where $a \in[0,1)$ and $L \geq 0$. 
Example 2. The function $F \in \mathcal{F}$, given by

$$
F\left(t_{1}, t_{2}, t_{3}, t_{4}, t_{5}, t_{6}\right)=t_{1}-a \max \left\{t_{2}, t_{3}, t_{4}, t_{5}, t_{6}\right\},
$$

where $a \in[0,1 / 2)$ satisfies properties $F_{2}$ and $F_{1 a}-F_{1 c}$ with $h=\frac{a}{1-a}<1$.

Motivated by [21], the following theorem is one of the main results in this article.

Theorem 1. Let $(X, d)$ be a metric space and $T, f: X \rightarrow X$ be self-mappings such that $T X \subseteq f X$. Assume that there exists $F \in \mathcal{F}$, satisfying $\left(F_{1 a}\right)$, such that for all $x, y \in X$

$$
F(d(T x, T y), d(f x, f y), d(f x, T x), d(f y, T y), d(f x, T y), d(f y, T x)) \leq 0 .
$$

If $f X$ is a complete subspace of $X$, then $T$ and $f$ have a coincidence point. Moreover, if $T$ and $f$ are weakly compatible and $F$ satisfies also $F_{2}$ then $T$ and $f$ have a unique common fixed point. Further, for any $x_{0} \in X$, the T-f-sequence $\left\{T x_{n}\right\}$ with initial point $x_{0}$ converges to the common fixed point.

Proof. Let $x_{0} \in X$ be an arbitrary point. As $T X \subseteq f X$, one can choose a $T$-f-sequence $\left\{T x_{n}\right\}$ with initial point $x_{0}$. If we take $x=x_{n}$ and $y=x_{n+1}$ in (1) and denote with $u=d$ $\left(T x_{n}, T x_{n+1}\right)$ and $v=d\left(T x_{n-1}, T x_{n}\right)$ we get that

$$
F\left(u, v, v, u, d\left(T x_{n-1}, T x_{n+1}\right), 0\right) \leq 0 .
$$

By triangle inequality, $d\left(T x_{n-1}, T x_{n+1}\right) \leq d\left(T x_{n-1}, T x_{n}\right)+d\left(T x_{n}, T x_{n+1}\right)=u+v$ and, since $F$ is non-increasing in the fifth variable, we have

$$
F(u, v, v, u, u+v, 0) \leq 0
$$

and hence, in view of assumption $\left(F_{1 a}\right)$, there exists $h \in[0,1)$ such that $u \leq h v$, i.e.,

$$
d\left(T x_{n}, T x_{n+1}\right) \leq h d\left(T x_{n-1}, T x_{n}\right) \quad \text { for all } n \in \mathbb{N} .
$$

By (2), in a straightforward way, we deduce that $\left\{T x_{n}\right\}$ is a Cauchy sequence. Since $f X$ is complete, there exist $z, w \in X$ such that $z=f w$ and

$$
\lim _{n \rightarrow+\infty} T x_{n}=\lim _{n \rightarrow+\infty} f x_{n}=f w=z .
$$

By taking $x=x_{n}$ and $y=w$ in (1), we obtain that

$$
F\left(d\left(T x_{n}, T w\right), d\left(f x_{n}, f w\right), d\left(f x_{n}, T x_{n}\right), d(f w, T w), d\left(f x_{n}, T w\right), d\left(f w, T x_{n}\right)\right) \leq 0 .
$$

As $F$ is continuous, using (3) and letting $n \rightarrow+\infty$ in (4), we get

$F(d(f w, T w), d(f w, f w), d(f w, f w), d(f w, T w), d(f w, T w), d(f w, f w)) \leq 0$

which, by assumption $\left(F_{1 a}\right)$, yields $d(f w, T w) \leq 0$, i.e., $f w=T w=z$. Thus, we have proved that $T$ and $f$ have a coincidence point.

Now, we assume that $T$ and $f$ are weakly compatible, then $f z=f T w=T f w=T z$.

We show that $T z=z=T w$.

Suppose $d(T z, T w)>0$, by taking $x=z$ and $y=w$ in (1), we get

$F(d(T z, T w), d(f z, f w), d(f z, T z), d(f w, T w), d(f z, T w), d(f w, T z)) \leq 0$,

i.e.,

$F(d(T z, T w), d(T z, T w), 0,0, d(T z, T w), d(T z, T w)) \leq 0$, 
which is a contradiction by assumption $\left(F_{2}\right)$. This implies that $d(T z, T w)=0$ and hence $f z=T z=T w=z$. So $T$ and $f$ have a common fixed point.

The uniqueness of the common fixed point is a consequence of assumption $\left(F_{2}\right)$. Clearly, for any $x_{0} \in X$, the $T$-f-sequence $\left\{T x_{n}\right\}$ with initial point $x_{0}$ converges to the unique common fixed point.

Remark 1. From (2) we deduce the unifying error estimate

$$
d\left(T x_{n+i-1}, z\right) \leq \frac{h^{i}}{1-h} d\left(T x_{n-1}, T x_{n}\right) .
$$

From this we get both the a priori estimate

$$
d\left(T x_{n}, z\right) \leq \frac{h^{n}}{1-h} d\left(T x_{0}, T x_{1}\right), \quad n=1,2, \ldots
$$

and the a posteriori estimate

$$
d\left(T x_{n}, z\right) \leq \frac{h}{1-h} d\left(T x_{n-1}, T x_{n}\right), \quad n=1,2, \ldots
$$

which are extremely important in applications, especially when approximating the solutions of nonlinear equations.

If $f=I_{X}$ from Theorem 1, we deduce the following result of fixed point for one selfmapping, see [21].

Corollary 1. Let $(X, d)$ be a complete metric space and $T: X \rightarrow X$. Assume that there exists, $F \in \mathcal{F}$ satisfying $\left(F_{1 a}\right)$, such that for all $x, y \in X$

$$
F(d(T x, T y), d(x, y), d(x, T x), d(y, T y), d(x, T y), d(y, T x)) \leq 0 .
$$

Then $T$ has a fixed point. Moreover, if $F$ satisfies also $F_{2}$, then $T$ has a unique fixed point. Further, for any $x_{0} \in X$, the Picard sequence $\left\{T^{n} x_{0}\right\}$ with initial point $x_{0}$ converges to the fixed point.

\section{Common fixed point in ordered metric spaces}

The existence of fixed points in ordered metric spaces was investigated by Turinici [39], Ran and Reurings [40], Nieto and Rodríguez-López [41]. See, also [42-45], and references therein. A common fixed point result in ordered metric spaces for mappings satisfying implicit contractive conditions is given by the next theorem.

Theorem 2. Let $(X, d, \lessgtr)$ be a complete ordered metric space and $T, f: X \rightarrow X$ be selfmappings such that $T X \subseteq f X$. Assume that there exists $F \in \mathcal{F}$, satisfying $\left(F_{1 a}\right)$, such that for all $x, y \in X$ with $f x \preccurlyeq f y$

$$
F(d(T x, T y), d(f x, f y), d(f x, T x), d(f y, T y), d(f x, T y), d(f y, T x)) \leq 0 .
$$

If the following conditions hold:

(i) there exists $x_{0} \in X$ such that $f x_{0} \leqslant T x_{0}$;

(ii) $T$ is $f$-non-decreasing;

(iii) for a non-decreasing sequence $\left\{f x_{n}\right\} \subseteq X$ converging to $f w \in X$, we have $f x_{n} \leqslant f w$ for all $n \in \mathbb{N}$ and $f w \leqslant f f w$;

then $T$ and $f$ have a coincidence point in $X$. Moreover, if

(iv) $T$ and $f$ are weakly compatible;

(v) $F$ satisfies also $F_{2}$, 
then $T$ and $f$ have a common fixed point. Further, for any $x_{0} \in X$, the $T$-f-sequence $\left\{T x_{n}\right\}$ with initial point $x_{0}$ converges to a common fixed point.

Proof. Let $x_{0} \in X$ such that $f x_{0} \leqslant T x_{0}$ and let $\left\{T x_{n}\right\}$ be a $T$-f-sequence with initial point $x_{0}$. Since $f x_{0} \leqslant T x_{0}$ and $T x_{0}=f x_{1}$, we have $f x_{0} \leqslant f x_{1}$. As $T$ is $f$-non-decreasing we get that $T x_{0} \leqslant T x_{1}$. Continuing this process we obtain

$$
f x_{0} \preccurlyeq T x_{0}=f x_{1} \preccurlyeq T x_{1}=f x_{2} \preccurlyeq \cdots \preccurlyeq T x_{n}=f x_{n+1} \preccurlyeq \cdots .
$$

In what follows we will suppose that $d\left(T x_{n}, T x_{n+1}\right)>0$ for all $n \in \mathbb{N}$, since if $T x_{n}=$ $T x_{n+1}$ for some $n$, then $f x_{n+1}=T x_{n}=T x_{n+1}$. This implies that $x_{n+1}$ is a coincidence point for $T$ and $f$ and the result is proved. As $f x_{n} \leqslant f x_{n+1}$ for all $n \in \mathbb{N}$, if we take $x=$ $x_{n}$ and $y=x_{n+1}$ in (5) and denote $u=d\left(T x_{n}, T x_{n+1}\right)$ and $v=d\left(T x_{n-1}, T x_{n}\right)$ we get that

$$
F\left(u, v, v, u, d\left(T x_{n-1}, T x_{n+1}\right), 0\right) \leq 0 .
$$

By triangle inequality, $d\left(T x_{n-1}, T x_{n+1}\right) \leq d\left(T x_{n-1}, T x_{n}\right)+d\left(T x_{n}, T x_{n+1}\right)=u+v$ and, since $F$ is non-increasing in the fifth variable, we have

$$
F(u, v, v, u, u+v, 0) \leq 0
$$

and hence, in view of assumption $\left(F_{1 a}\right)$, there exists $h \in[0,1)$ such that $u \leq h v$, i.e.,

$$
d\left(T x_{n}, T x_{n+1}\right) \leq h d\left(T x_{n-1}, T x_{n}\right) .
$$

By (6), we deduce that $\left\{T x_{n}\right\}$ is a Cauchy sequence. Since $(X, d)$ is complete, there exist $z, w \in X$ such that $z=f w$ and

$$
\lim _{n \rightarrow+\infty} T x_{n}=\lim _{n \rightarrow+\infty} f x_{n}=f w=z .
$$

By condition (iii), $f x_{n} \leqslant f w$ for all $n \in \mathbb{N}$, if we take $x=x_{n}$ and $y=w$ in (5) we get

$$
F\left(d\left(T x_{n}, T w\right), d\left(f x_{n}, f w\right), d\left(f x_{n}, T x_{n}\right), d(f w, T w), d\left(f x_{n}, T w\right), d\left(f w, T x_{n}\right) \leq 0 .\right.
$$

As $F$ is continuous, using (7) and letting $n \rightarrow+\infty$ we obtain

$$
F(d(f w, T w), d(f w, f w), d(f w, f w), d(f w, T w), d(f w, T w), d(f w, f w)) \leq 0
$$

which, by assumption $\left(F_{1 a}\right)$, yields $d(f w, T w) \leq 0$, i.e., $f w=T w$. Thus we have proved that $T$ and $f$ have a coincidence point.

If $T$ and $f$ are weakly compatible we show that $z$ is a common fixed point for $T$ and $f$ . As $f z=f T w=T f w=T z$, by condition (iii), we have that $f w \preccurlyeq f f w=f z$.

Now, by taking $x=w$ and $y=z$ in (5) we get

$$
F(d(T w, T z), d(f w, f z), d(f w, T w), d(f z, T z), d(f w, T z), d(f z, T w)) \leq 0 .
$$

Assumption $\left(F_{2}\right)$ implies $d(T z, T w)=0$ and hence $f z=T z=T w=z$. So $T$ and $f$ have a common fixed point. From the proof it follows that, for any $x_{0} \in X$, the $T-f$ -sequence $\left\{T x_{n}\right\}$ with initial point $x_{0}$ converges to a common fixed point. $\square$

We shall give a sufficient condition for the uniqueness of the common fixed point in Theorem 2.

Theorem 3. Let all the conditions of Theorem 2 be satisfied. If the following conditions hold

(vi) for all $x, y \in f X$ there exists $v_{0} \in X$ such that $f v_{0} \leqslant x, f v_{0} \leqslant y$;

(vii) $F$ satisfies $F_{1 c}$, 
then $T$ and $f$ have a unique common fixed point.

Proof. Let $z, w$ be two common fixed points of $T$ and $f$ with $z \neq w$. If $z$ and $w$ are comparable, say $z \leqslant y$. Then taking $x=z$ and $y=w$ in (5), we obtain

$$
F(d(T z, T w), d(f z, f w), d(f z, T z), d(f w, T w), d(f z, T w), d(f w, T z)) \leq 0,
$$

which is a contradiction by assumption $\left(F_{2}\right)$ and so $z=w$.

If $z$ and $w$ are not comparable, then there exists $v_{0} \in X$ such that $f v_{0} \leqslant f z=z$ and $f v_{0}$ $\preccurlyeq f w=w$.

As $T$ is $f$-non-decreasing from $f v_{0} \preccurlyeq f z$ we get that

$$
f v_{1}=T v_{0} \preccurlyeq T z=f z .
$$

Continuing we obtain

$$
f v_{n+1}=T v_{n} \preccurlyeq T z=f z \text { for all } n \in \mathbb{N} .
$$

Then, taking $x=v_{n}$ and $y=z$ in (5) we obtain

$$
F\left(d\left(T v_{n}, T z\right), d\left(f v_{n}, f z\right), d\left(f v_{n}, T v_{n}\right), d(f z, T z), d\left(f v_{n}, T z\right), d\left(f z, T v_{n}\right)\right) \leq 0,
$$

i.e.,

$$
F\left(d\left(T v_{n}, T z\right), d\left(T v_{n-1}, T z\right), d\left(T v_{n-1}, T v_{n}\right), d(f z, T z), d\left(T v_{n-1}, T z\right), d\left(T z, T v_{n}\right)\right) \leq 0 .
$$

Denote $u=d\left(T v_{n}, T z\right)$ and $v=d\left(T v_{n-1}, T z\right)$. As $F$ is non-increasing in the third variable, we get

$$
F(u, v, u+v, 0, v, u) \leq 0 .
$$

By assumption $F_{1 c}$, there exists $h \in[0,1)$ such that $u \leq h v$, i.e.,

$$
d\left(T v_{n}, T z\right) \leq h d\left(T v_{n-1}, T z\right), \quad \text { for all } n \in \mathbb{N} .
$$

This implies that $d\left(T v_{n}, T z\right)=d\left(T v_{n}, z\right) \rightarrow 0$ as $n \rightarrow+\infty$.

With similar arguments, we deduce that $d\left(T v_{n}, w\right) \rightarrow 0$ as $n \rightarrow+\infty$. Hence

$$
0<d(w, z) \leq d\left(w, T v_{n}\right)+d\left(T v_{n}, z\right) \rightarrow 0
$$

as $n \rightarrow+\infty$, which is a contradiction. Thus $T$ and $f$ have a unique common fixed point. $\square$

If $f=I_{X}$ from Theorems 2 and 3, we deduce the following results of fixed point for one self-mapping.

Corollary 2. Let $(X, d, \preccurlyeq)$ be a complete ordered metric space and $T: X \rightarrow X$. Assume that there exists $F \in \mathcal{F}$, satisfying $\left(F_{1 a}\right)$, such that for all $x, y \in X$ with $x \leqslant y$

$$
F(d(T x, T y), d(x, y), d(x, T x), d(y, T y), d(x, T y), d(y, T x)) \leq 0 .
$$

\section{If the following conditions hold:}

(i) there exists $x_{0} \in X$ such that $x_{0} \leqslant T x_{0}$;

(ii) $T$ is non-decreasing;

(iii) for a non-decreasing sequence $\left\{x_{n}\right\} \subseteq X$ converging to $w \in X$, we have $x_{n} \leqslant w$ for all $n \in \mathbb{N}$,

then $T$ has a fixed point in X. Further, for any $x_{0} \in X$, the Picard sequence $\left\{T^{n} x_{0}\right\}$ with initial point $x_{0}$ converges to a fixed point. 
Corollary 3. Let all the conditions of Corollary 2 be satisfied. If the following conditions hold

(v) $F$ satisfies $F_{2}$;

(vi) for all $x, y \in X$ there exists $v_{0} \in X$ such that $v_{0} \leqslant x, v_{0} \leqslant y$;

(vii) $F$ satisfies $F_{1 c}$,

then $T$ has a unique fixed point.

If $F$ is the function in Example 2, then by Theorem 3 we obtain a fixed point theorem that extends the result of Theorem 3 of [44].

\section{Acknowledgements}

The first author research's was supported by the Grant PN-II-RU-TE-2011-3-239 of the Romanian Ministry of Education and and Research.

\section{Authors' Contributions}

All authors contributed equally and significantly in writing this article. All authors read and approved the final manuscript.

\section{Competing interests}

The author declares that they have no competing interests.

Received: 18 April 2012 Accepted: 24 June 2012 Published: 24 June 2012

\section{References}

1. Banach, S: Sur les opérations dans les ensembles abstraits et leur application aux équations intégrales. Fund Math. 3, 133-181 (1922)

2. Rus, IA: Generalized Contractions and Applications. Cluj University Press, Cluj-Napoca (2001)

3. Rus, IA, Petruşel, A, Petruşel, G: Fixed Point Theory. Cluj University Press, Cluj-Napoca (2008)

4. Reem, D, Reich, S, Zaslavski, AJ: Two results in metric fixed point theory. J Fixed Point Theory Appl. 1, 149-157 (2007). doi:10.1007/s11784-006-0011-4

5. Reich, S, Zaslavski, AJ: A fixed point theorem for Matkowski contractions. Fixed Point Theory. 8, 303-307 (2007)

6. Reich, S, Zaslavski, AJ: A note on Rakotch contraction. Fixed Point Theory. 9, 267-273 (2008)

7. Berinde, $\mathrm{V}$ : On the approximation of fixed points of weak contractive mappings. Carpathian J Math. 19, 7-22 (2003)

8. Berinde, V: Approximating fixed points of weak $\varphi$-contractions. Fixed Point Theory. 4, 131-142 (2003)

9. Berinde, V: Approximation fixed points of weak contractions using the Picard iteration. Nonlinear Anal Forum. 9, 43-53 (2004)

10. Berinde, V: Error estimates for approximating fixed points of quasi contractions. Gen Math. 13, 23-34 (2005)

11. Berinde, V: Approximation of Fixed Points. Springer, Berlin, Heidelberg, New York (2007)

12. Berinde, V: General constructive fixed point theorems for Cirić-type almost contractions in metric spaces. Carpathian J Math. 24, 10-19 (2008)

13. Berinde, V: Some remarks on a fixed point theorem for Ćirić-type almost contractions. Carpathian J Math. 25, 157-162 (2009)

14. Berinde, $\mathrm{V}$ : Approximating common fixed points of noncommuting almost contractions in metric spaces. Fixed Point Theory. 11, 179-188 (2010)

15. Berinde, $\mathrm{V}$ : Common fixed points of noncommuting almost contractions in cone metric spaces. Math Commun. 15 , 229-241 (2010)

16. Popa, V: Fixed point theorems for implicit contractive mappings. Stud Cerc St Ser Mat Univ Bacău. 7, 127-133 (1997)

17. Popa, V: Some fixed point theorems for compatible mappings satisfying an implicit relation. Demonstratio Math. 32 , 157-163 (1999)

18. Ali, J, Imdad, M: Unifying a multitude of common fixed point theorems employing an implicit relation. Commun Korean Math Soc. 24, 41-55 (2009). doi:10.4134/CKMS.2009.24.1.041

19. Aliouche, A, Djoudi, A: Common fixed point theorems for mappings satisfying an implicit relation without decreasing assumption. Hacet J Math Stat. 36, 11-18 (2007)

20. Aliouche, A, Popa, V: General common fixed point theorems for occasionally weakly compatible hybrid mappings and applications. Novi Sad J Math. 39, 89-109 (2009)

21. Berinde, V: Approximating fixed points of implicit almost contractions. Hacet J Math Stat. 40, 93-102 (2012)

22. Popa, V: A general fixed point theorem for weakly compatible mappings in compact metric spaces. Turkish J Math. 25, 465-474 (2001)

23. Popa, V: Fixed points for non-surjective expansion mappings satisfying an implicit relation. Bul Stiint Univ Baia Mare Ser B. 18, 105-108 (2002)

24. Popa, V: A general fixed point theorem for four weakly compatible mappings satisfying an implicit relation. Filomat. 19, 45-51 (2005)

25. Popa, V, Imdad, M, Ali, J: Using implicit relations to prove unified fixed point theorems in metric and 2-metric spaces. Bull Malays Math Sci Soc. 33, 105-120 (2010)

26. Abbas, M, llic, D: Common fixed points of generalized almost nonexpansive mappings. Filomat. 24(3), 11-18 (2010). doi:10.2298/FIL1003011A 
27. Babu, GVR, Sandhy, ML, Kameshwari, MVR: A note on a fixed point theorem of Berinde on weak contractions. Carpathian J Math. 24, 8-12 (2008)

28. Berinde, V: Stability of Picard iteration for contractive mappings satisfying an implicit relation. Carpathian J Math. 27 13-23 (2011)

29. Chatterjea, SK: Fixed-point theorems. C R Acad Bulgare Sci. 25, 727-730 (1972)

30. Hardy, GE, Rogers, TD: A generalization of a fixed point theorem of Reich. Canad Math Bull. 16, 201-206 (1973). doi:10.4153/CMB-1973-036-0

31. Kannan, R: Some results on fixed points. Bull Calcutta Math Soc. 10, 71-76 (1968)

32. Reich, S: Fixed points of contractive functions. Boll Un Mat Ital. 5, 26-42 (1972)

33. Reich, S: Kannan's fixed point theorem. Boll Un Mat Ital. 4, 1-11 (1971)

34. Reich, S: Some remarks concerning contraction mappings. Can Math Bull. 14, 121-124 (1971). doi:10.4153/CMB-1971024-9

35. Rhoades, BE: A comparison of various definitions of contractive mappings. Trans Am Math Soc. 226, 257-290 (1977)

36. Rhoades, BE: Contractive definitions revisited. Contemp Math. 21, 189-205 (1983)

37. Rhoades, BE: Contractive definitions and continuity. Contemp Math. 72, 233-245 (1988)

38. Zamfirescu, T: Fix point theorems in metric spaces. Arch Math (Basel). 23, 292-298 (1972). doi:10.1007/BF01304884

39. Turinici, M: Abstract comparison principles and multivariable Gronwall-Bellman inequalities. J Math Anal Appl. 117, 100-127 (1986). doi:10.1016/0022-247X(86)90251-9

40. Ran, ACM, Reurings, MC: A fixed point theorem in partially ordered sets and some applications to matrix equations. Proc Am Math Soc. 132, 1435-1443 (2004). doi:10.1090/50002-9939-03-07220-4

41. Nieto, JJ, Rodríguez-López, R: Contractive mapping theorems in partially ordered sets and applications to ordinary differential equations. Order. 22, 223-239 (2005). doi:10.1007/s11083-005-9018-5

42. Cherichi, M, Samet, B: Fixed point theorems on ordered gauge spaces with applications to non-linear integral equations. Fixed Point Theory Appl. 2012, 13 (2012). doi:10.1186/1687-1812-2012-13

43. Cirić, L, Agarwal, RP, Samet, B: Mixed monotone-generalized contractions in partially ordered probabilistic metric spaces. Fixed Point Theory Appl. 2011, 56 (2011). doi:10.1186/1687-1812-2011-56

44. Golubović, Z, Kadelburg, Z, Radenović, S: Common fixed points of ordered g-quasicontractions and weak contractions in ordered metric spaces. Fixed Point Theory Appl. 2012, 20 (2012). doi:10.1186/1687-1812-2012-20

45. Samet, B: Coupled fixed point theorems for a generalized Meir-Keeler contraction in partially ordered metric spaces. Nonlinear Anal. 72, 4508-4517 (2010). doi:10.1016/..na.2010.02.026

doi:10.1186/1687-1812-2012-105

Cite this article as: Berinde and Vetro: Common fixed points of mappings satisfying implicit contractive conditions. Fixed Point Theory and Applications 2012 2012:105.

\section{Submit your manuscript to a SpringerOpen ${ }^{\circ}$ journal and benefit from:}

- Convenient online submission

- Rigorous peer review

- Immediate publication on acceptance

- Open access: articles freely available online

- High visibility within the field

- Retaining the copyright to your article

Submit your next manuscript at $\boldsymbol{\wedge}$ springeropen.com 